\title{
Titanium Influence on the Microstructure of FeCrAl Alloys Used for 4R Generation Nuclear Power Plants
}

\author{
VICTOR GEANTA ${ }^{1}$, IO NELIA VOICULESCUㄹ, RADU STEFANOIU ${ }^{1 *}$, ADRIAN J IANU², IOAN MILOSAN ${ }^{3}$, ELENA MANUELA STANCIU³, \\ ALEXANDRU PASCU ${ }^{3}$, ION MIHAI VASILE $^{1}$ \\ 1Politehnica University of Bucharest, 313 Splaiul Independentei, 060042, Bucharest, Romania \\ ${ }^{2}$ Karlsruhe Insititute of Technology - Institute for Pulsed Power and Microwave Technology, Campus Nord, Bldg. 421, Hermann- \\ von- Helmholtz-Platz 1, 76344 Eggenstein-Leopoldshafen, Germany \\ ${ }^{3}$ Transilvania University of Brasov, 29 Eroilor Blvd., 500036, Brasov, Romania
}

\begin{abstract}
$4 R$ generation nuclear power plants should work with metallic material of the highest quality, capable to resist in maximum safe conditions for 25-30 years. FeCrAl alloys are capable of such performance, because of the resistance to: oxidation at high temperatures, corrosion, erosion and penetrating radiations in liquid metal environments. In addition, such materials are capable of forming on their surface some oxide layers, textured and self-renewable, with high adhesion to metallic substrates. These properties can be improved by microalloying with metal elements such as Ti, Zr, Y, Hf in amounts of 1 to 3\%. These chemical elements have high affinity to oxygen, being able to stabilize the structure of the superficial layer of oxide (alumina) and to increase adhesion to the metallic substrate. The FeCrAl alloys microalloyed with titanium were obtained in a VAR (Vacuum Arc Remelting) equipment in argon atmosphere (99.99\% purity). There were obtained three batches microalloyed with $0.5 \%, 1 \%$ and $1.5 \%$ titanium, preserving the same Fe-14Cr-5Al metal matrix. In order to determine the chemical composition of the oxide layer and of the sample bulk, the EDAX analysis was performed. Microstructural features were revealed using SEM analysis. The results showed the capacity of the FeCrAl alloy to form oxide layers, with different textures and rich in elements such as Al and Ti. The compositional analysis performed on FeCrAl samples microalloyed with 0.5, 1.0 and 1.5\% Ti in the central zone shows a relatively similar composition compared to the technological calculations made, reflecting the homogeneity of the alloy. The microhardness measurements performed on the cross sections of the metallic samples attest values in the range 163-183 $\mathrm{HV}$, falling within the normal range for these materials. These values are influenced by the presence of the alloying elements in the metallic matrix and by the homogeneous arrangement of constituents.
\end{abstract}

Keywords: FeCrAl alloys; titanium; chemical composition; microhardness; microstructure.

Molten lead or lead-bismuth eutectic (LBE) is considered an attractive coolant for various nuclear applications, especially generation fourth (Gen-IV) and small- and medium-sized reactor (SMR) ones. Its low melting point, low reactivity, low vapour pressure, low viscosity, good gamma shielding, high boiling point, excellent chemical stability, lack of fire or explosion risk, as well as neutron transparencyand high neutron yield make LBE-cooled reactors and spallation sources good candidates for advanced energy systems. The main difficulty in using LBE as a coolant lies actually in understanding and controlling the corrosion of candidate structural materials in LBE. It is believed that protective oxide layers can be formed on LBEexposed steel in order to prevent further corrosion, while ensuring that oxide layers formed on steels are able to resist to the system operating conditions (high flow rate, high temperature etc.) for a long period of time (25 - 30 years in the case of reactors).

As a coolant for fast reactor systems, liquid lead or leadbismuth eutectic (LBE) provides two advantages over liquid sodium. First, lead alloys do not react exothermically with water or air as sodium does. Second, the boiling temperature of lead alloys is much higher than that of sodium, providing greater safety margins and the ability to operate at higher temperature.

The development of lead alloy coolant technologies will allow successful application with maximized efficiency and enhanced safety.The LBE-cooled nuclear energy systems, however, have been exposed to several issues arising from the limitation of the system life due to the relatively low corrosion resistance of structural materials in LBE environments. The corrosion behaviours on several types of austenitic and ferritic/martensitic (FM) steels have been extensively studied to investigate the corrosion performance of structural materials and to improve the materials life performance worldwide [1-9].

The resistance of structural alloys to rapid degradation in aggressive environments at elevated temperatures usually depends on the ability of the alloys to form and maintain a protective reaction product scale.

In recent years, substantial efforts have been made to investigate and improve the resistance of candidate materials to typical corrosion mechanisms observed in liquid lead/lead alloys, which are dissolution attacks (loss of alloying elements) and/or extensive oxide scale growths. These research activities showed that thin, slow-growing oxide scale can represent a suitable corrosion barrier for long term protection and adequate heat transfer (important in core components) $[10,11]$.

FeCrAl alloys, along with the ZrCrAl alloys class, can be used to achieve the metallic structures of the reactor in nuclear power plants, generation 4R. The components that can be made from these modern alloys are: outer jacket of the reactor, recirculation pipes for the liquid metal, pumps for the distribution of the cooling medium etc. Modern type LFR reactors working in closed cycle with optional fuel flexibility and fast neutron spectrum are cooled with metallic media like $\mathrm{Pb}$ or $\mathrm{Pb}-\mathrm{Bi}$ alloys. This particularity 
ensures a much higher level of security at a lower overall volume compared to the previous generation reactors. Such materials must provide excellent mechanical and technological characteristics, among which: plasticity and ductility, mechanical workability, weldability, thermal shock resistance and mechanical strength, creep resistance at high temperature, high chemical stability in specific environmental conditions (temperatures above 400 - 800 $\left.{ }^{\circ} \mathrm{C}\right)$, corrosion and erosion resistance, high thermal conductivity to ensure optimum heat transfer.

Iron-chromium-aluminium alloys containing 15-20 wt.\% $\mathrm{Cr}$ and $4-6 \mathrm{wt} . \% \mathrm{Al}$ have shown excellent corrosion resistance in the temperature range up to $600^{\circ} \mathrm{C}$ or higher in liquid lead and lead-bismuth eutectic environments by forming protective $\mathrm{Al}_{2} \mathrm{O}_{3}$ layers. However, higher $\mathrm{Cr}$ and $\mathrm{Al}$ because of severe embrittlement in the manufacturing process as well as in use, caused by the formation of brittle phases. The resistance of FeCrAl alloys to high-temperature oxidation depends on the properties of the built-up aluminium oxide $[12,13]$.

The design of new alloys was focused on the optimization of $\mathrm{Cr}$ and $\mathrm{Al}$ levels for the formation of an external $\mathrm{Al}_{2} \mathrm{O}_{3}$ layer which can provide excellent oxidation and corrosion resistance in liquid lead alloys in the temperature range $400-600^{\circ} \mathrm{C}$ without severe embrittlement caused by the formation of brittle phases such as $\mathrm{Cr}$-rich $\alpha^{\prime}$ and $\sigma$ phase precipitates.

Minor amounts of reactive elements (RE's), e.g. Y, Hf, $\mathrm{Zr}$, Ti and Ce are usually mixed into FeCrAl alloys to improve oxidation properties atelevated temperatures. All elements may oxidise in an FeCrAl alloy depending on the temperature and the exposure environment. Initially (during heating), all elements present at the alloy surface will oxidise and form a mixed oxide scale called transient oxide.An addition of reactive elements, particularly Zr and $\mathrm{Hf}$, results in better adhesion of the scale to the base.

The effectiveness of $\mathrm{Zr}$ stems from the fact that the latter quickly penetrates into the scale, changing its morphology (the column structure is replaced by small equiaxial grains), producing pores and $\mathrm{ZrO}$, inclusions in it and preventing chromium carbides from forming at grain boundaries [14 - 17].

Two main positive effects of the RE addition on the oxidation resistance of alumina forming alloys are accepted. The first one is the suppression of the outward diffusion of Al-cations in the alumina scale. This results in a decrease in the oxidation rate and changes in the scale structure and morphology. The second important RE-effect is attributed to the prevention of the deleterious sulphur segregation on the scale/metal interface.

Yttrium was added to enhance the oxidation resistance at elevated temperatures. The addition of such reactive elements is known to reduce the growth rate of the alumina scales and to improve the adherence resulting in improved oxidation resistance compared to that of base alloys which do not contain yttrium.

Hafnium is used for nuclear reactor control rods because of its ability to absorb neutrons and its good mechanical and corrosion resistance qualities. Its neutron-capture cross-section is about 600 times larger than that of zirconium. Hafnium resists to corrosion due to the formation of an oxide film on exposed surfaces. In FeCrAl alloys microalloyed with hafnium, a complex aluminium oxide that contains both aluminium and hafnium forms on the metallic surface. The physical properties of hafnium metal samples are markedly affected by zirconium impurities, especially the nuclear properties, as these two concentrations in ferritic alloys could be problematic

elements are among the most difficult to separate because of their chemical similarity.

Titanium is an alpha phase stabiliser, having limited solubility in the ferrite due to the formation of compound $\mathrm{Fe}$ Ti. Titanium reacts with oxygen at temperatures of 600 $800^{\circ} \mathrm{C}$ according to the reaction:

$$
\mathrm{Ti}(\mathrm{s})+\mathrm{O}_{2}(\mathrm{~g})---->>\mathrm{TiO}_{2}(\mathrm{~s}) \text {. }
$$

Titanium has high affinity for oxygen, which means that it takes part in the deoxidation processes of the molten metal. The affinity of titanium for oxygen can be evaluated using the equilibrium constant $\left(\mathrm{K}_{\mathrm{Ti}}=[\mathrm{Ti}][\mathrm{O}]^{2}\right)$, considering that the total amount formed varies with the temperature according to:

$$
\log \mathrm{K}_{\mathrm{Ti}}=38828 / \mathrm{T}+11.95
$$

Since the $\mathrm{K}_{\text {Tा }}$ value is $6.638 \times 10^{-8}$ at $1600{ }^{\circ} \mathrm{C}$, it follows that the deoxidation power of titanium is greater comparatively with silicon and aluminium. Titanium is also used as a deoxidizer and as an alloying element in ferrous alloys like FeCrAl. In addition, titanium has a strong effect on the precipitation of sulphides in metallic alloys $[18,19]$.

The paper presents several results related to how the presence of titanium into the experimental alloys, FeCrAl type, influence the formation and stability of superficial oxide layers. Some chemical composition analyses are performed both in the oxide crust and in the material volume, compared with the values of microhardness measurements. It was found that the experimental alloys obtained show a good microstructural homogeneity, balanced distribution of alloying elements and microhardness values within the usual limits for this class.

\section{Experimental part}

\section{Materilas and methods}

The aim of the research were to design and manufacture FeCrAl alloys as mini-ingot, using a VAR (Vacuum Arc Remelting) furnace, documenting the procedure and analysing the microstructure in order to estimate the effect of the addition of titanium on the alloys' characteristics. The samples were designed and manufactured in the ERAMET laboratory, at the Politehnica University of Bucharest, Material Science and Engineering Faculty (www.eramet.wix.com/eramet), using a MRF ABJ 900 furnace [21]. Three experimental FeCrAl alloys were obtained, with different contents of titanium: $0.5 \% \mathrm{wt} \mathrm{Ti}$, $1.0 \% \mathrm{wt} \mathrm{Ti}$ and $1.5 \% \mathrm{wt} \mathrm{Ti}$, added into the same metallic matrix of the experimental alloy Fe-14Cr-5Al.

The raw material was a high purity extra softsteel, mark MK3, having the chemical composition: $\mathrm{C}=0.02 \% \mathrm{wt}$, Si $=0.04 \% \mathrm{wt}, \mathrm{Mn}=0.21 \% \mathrm{wt}, \mathrm{S}=0.02 \% \mathrm{wt}, \mathrm{P}=0.015 \%$ wt, $\mathrm{Ni}=0.2 \% \mathrm{wt}, \mathrm{Cr}=0.15 \% \mathrm{wt}, \mathrm{Mo}=0.07 \% \mathrm{wt}, 0.14 \%$ wt $\mathrm{Cu}, \mathrm{Al}=0.12 \%$ wt and $\mathrm{Fe}=$ bal.

For obtaining the high alloyed material, high purity alloying elements were introduced into the base material: metallic chromium $99.5 \%$ Cr; electrolytic aluminium 99.4 $\%$ Al; titanium $99.5 \%$ purity. The raw material on the plate of the VAR equipment is presented in fig. 1. After obtaining the stable vacuum of $1 \times 10^{-4} \mathrm{mBar}$, the furnace chamber was filled with argon (Ar 5.3) to insure the electric arc stability. Each mini-ingot was remelted and solidified five times, in order to obtain the microstructural homogeneity (fig. 2).

The assimilation coefficient for this particular alloy class was over $99.5 \%$, due to the low vapour losses of the components in the electric arc remelting process. Mini ingots had quasi-constant weight ( $39.63 \mathrm{~g}-39.96 \mathrm{~g}$ ) (table 1). 


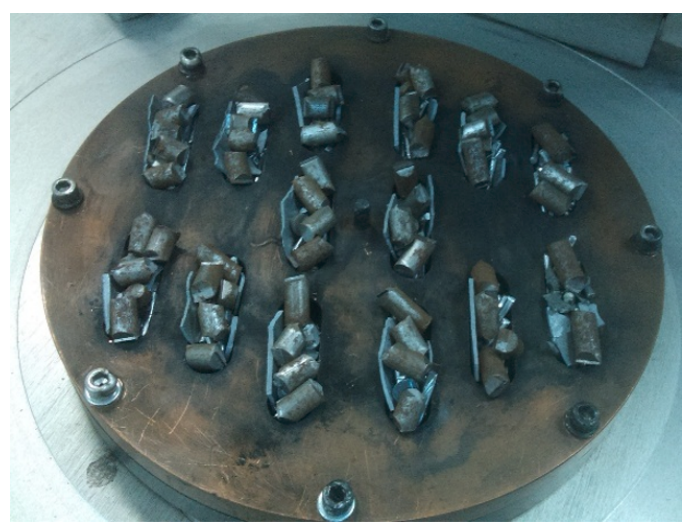

Fig. 1 The raw material on the plate of VAR equipment

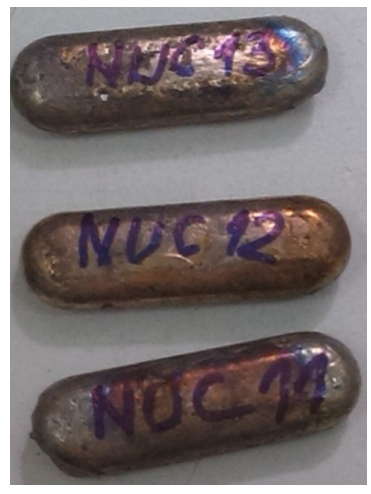
VAR equipment estimate the distribution of the chemical elements in the superficial oxide layer [20-23].

The microstructural analysis was conducted using a scanning electron microscope FEI QUANTA INSPECT F provided with electron gun with field emission - EGF with a resolution of $1.2 \mathrm{~nm}$ and a X-ray spectrometer energy dispersive (EDS) with resolution of $133 \mathrm{eV}$ at MnK [25].

\section{Chemical composition and microstructural analysis}

The chemical composition of the samples was determined by EDAX analysis in three successive zones (point 1 located on the surface layer, point 2 located at around 15 im below the surface and point 3 located in the middle of the sample), in accordance with figure 3. The

Fig. 2 Mini-ingot of FeCrAl obtained in

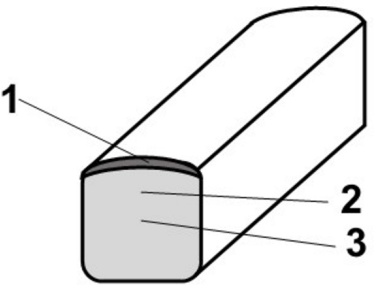

Fig. 3. Location of chemical analysis in cross sections of FeCrAITi alloys

chemical analysis values obtained for the three samples NUC 11, NUC 12 and NUC 13 in the centre zone (point 3) of the cross section samples are shown in table 2 .

The concentration analysis of chemical elements in the centre of the samples (point3) shows a good concordance

\begin{tabular}{|c|c|c|c|c|}
\hline Sample code & $\begin{array}{c}\text { Initial weight } \\
\text { batch, g }\end{array}$ & $\begin{array}{c}\text { Weight of } \\
\text { mini-ingot, g }\end{array}$ & $\begin{array}{c}\text { Assimilation } \\
\text { efficiency, } \\
\left(\mathrm{G}_{\text {ling }} / \mathrm{G}_{\mathrm{ch}}\right) \mathrm{x} 100, \%\end{array}$ & $\begin{array}{c}\text { Global efficiency, } \\
\%\end{array}$ \\
\hline NUC 11 - Fe-14Cr-5Al-0.5Ti & 40.0 & 39.96 & 99.90 & 99.58 \\
\hline NUC 12 - Fe-14Cr-5Al-1.0Ti & 40.0 & 39.91 & 99.77 & \\
\hline NUC13 - Fe-14Cr-5Al-1.5Ti & 40.0 & 39.63 & 99.07 & \\
\hline
\end{tabular}

Table 1

THE ASSIMILATION EFFICIENCY AND THE WEIGHT VALUES FOR EACH EXPERIMENTAL BATCH AND MINI-INGOT

\begin{tabular}{|c|c|c|c|c|c|}
\hline \multicolumn{6}{|c|}{ Chemical composition, $\%$ wt } \\
\hline \multicolumn{2}{|c|}{ NUCII } & \multicolumn{2}{|c|}{ NUC12 } & \multicolumn{2}{|c|}{ NUC13 } \\
\hline $\mathrm{OK}$ & - & $\mathrm{OK}$ & 0.66 & OK & - \\
\hline $\mathrm{AlK}$ & 5.12 & AlK & 4.44 & $\mathrm{AlK}$ & 4.47 \\
\hline $\mathrm{CrK}$ & 14.53 & $\mathrm{CrK}$ & 14.43 & $\mathrm{CrK}$ & 17.05 \\
\hline FeK & 79.71 & $\mathrm{FeK}$ & 79.74 & FeK & 77.6 \\
\hline TiK & 0.55 & $\mathrm{TiK}$ & 0.93 & $\mathrm{TiK}$ & 1.88 \\
\hline
\end{tabular}

\begin{tabular}{|c|c|c|c|c|c|}
\hline \multicolumn{6}{|c|}{ Chemical composition, \% wt } \\
\hline \multicolumn{2}{|c|}{ NUC11 $(0.5 \%$ wt Ti $)$} & \multicolumn{2}{|c|}{ NUC12 $(1.0 \%$ wt Ti) } & \multicolumn{2}{|c|}{$\mathrm{NUC13}(1.5 \%$ wt Ti) } \\
\hline OK & 42.84 & $O K$ & 11.07 & OK & 10.59 \\
\hline $\mathrm{AlK}$ & 55.34 & AIK & 17.34 & AIK & 29.2 \\
\hline $\mathrm{CaK}$ & - & $\mathrm{CaK}$ & 2.2 & $\mathrm{CaK}$ & - \\
\hline $\mathrm{CrK}$ & - & $\mathrm{CrK}$ & 10.33 & $\mathrm{CrK}$ & 10.57 \\
\hline $\mathrm{FeK}$ & - & $\mathrm{FeK}$ & 56.84 & $\mathrm{FeK}$ & 45.43 \\
\hline TiK & 1.82 & $\mathrm{TiK}$ & 2.22 & $\mathrm{TiK}$ & 4.22 \\
\hline
\end{tabular}

Table 2

CHEMICAL COMPOSITION OF ALLOYING ELEMENTS IN THE CENTRE OF THE SAMPLES

\section{Results and discussions}

Each cross section sectioned from the mini-ingots was processed according to the metallographic procedure using abrasive grit paper, followed by a final polishing using alumina alpha powder. The metallographic analysis was performed with the aim of highlighting the microstructural characteristics of the experimental alloys, in order to between the design of the FeCrAl alloyed with $\mathrm{Ti}$ and the chemical composition performed for each batch separately. At about $15.45 \mu \mathrm{m}$ below the surface of the cross section, the chemical composition of all mini ingots is similar with the one designed for FeCrAl alloys without microalloying elements (point 2). Table 3 shows the 
chemical compositions of the edge zone of the cross section for the three samples (point 1).

The chemical composition of the edge zone of the samples microalloyed with titanium indicates that the value of the Ti content is increasing with the increase of the titanium amount in the alloy. This value decreases in the direction of points 1 to 3 due the migration of this element toward the marginal zone, where itcombines with the oxygen dissolved in the sample. Because of the simultaneous presence of the two elements with very high affinity for oxygen (aluminium and titanium), complex oxides of $\mathrm{Al}$ and $\mathrm{Ti}$ are formed in the marginal crust and their share is given by the amounts of these elements in the alloy.

In the case of the sample NUC11, due to the small amount of Ti in the alloy, the superficial oxide layer is discontinuous (like isolated islands) and does not contain large amounts of titanium oxide, but there are predomir i idenced

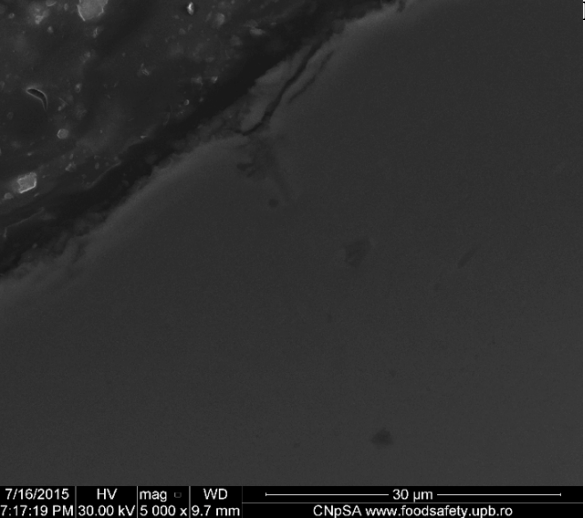

Fig. 4. Discontinuous layer of surface oxides, containing mainly alumina in the NUC11 sample

by the high amounts of aluminium compared to the low quantities of titanium. The oxide thickness is variable,

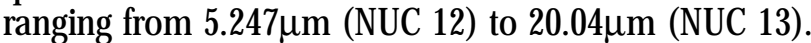

The surface layer of the NUC12 sample (fig. 5) contains some small areas rich in titanium oxides, while in sample NUC13 the surface layer contains complex oxide (Ti + Al), lens shaped (fig. 6). The concentration of titanium in the surface layer increases with the increase of the total

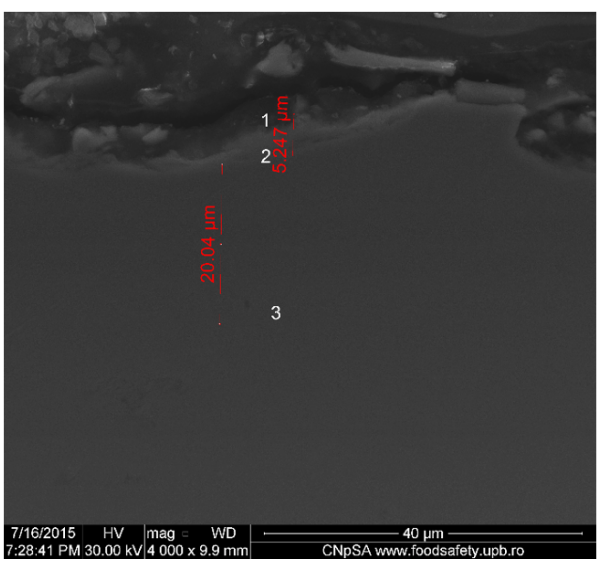

Fig. 5 Discontinuous layer of surface oxides, containing mainly alumina in the NUC12 sample

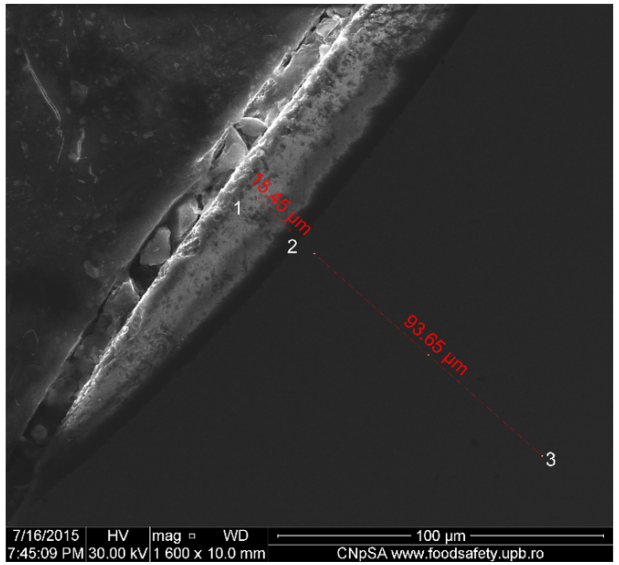

Fig. 6. Lens-shaped external oxides layer on the NUC 13 surface

amount of this element in the alloy. The elemental distribution of the elements present in the surface layer shows the correlation between the amounts of elements present in the oxide layer for each sample separately, i.e. $\mathrm{Fe}, \mathrm{Cr}, \mathrm{Al}, \mathrm{Ti}$. A representative distribution of the chemical elements in the oxide layer of NUC13 sample is shown in figure 7. Distribution image of X-radiation relative intensity for the main chemical elements detected by EDS analysis:

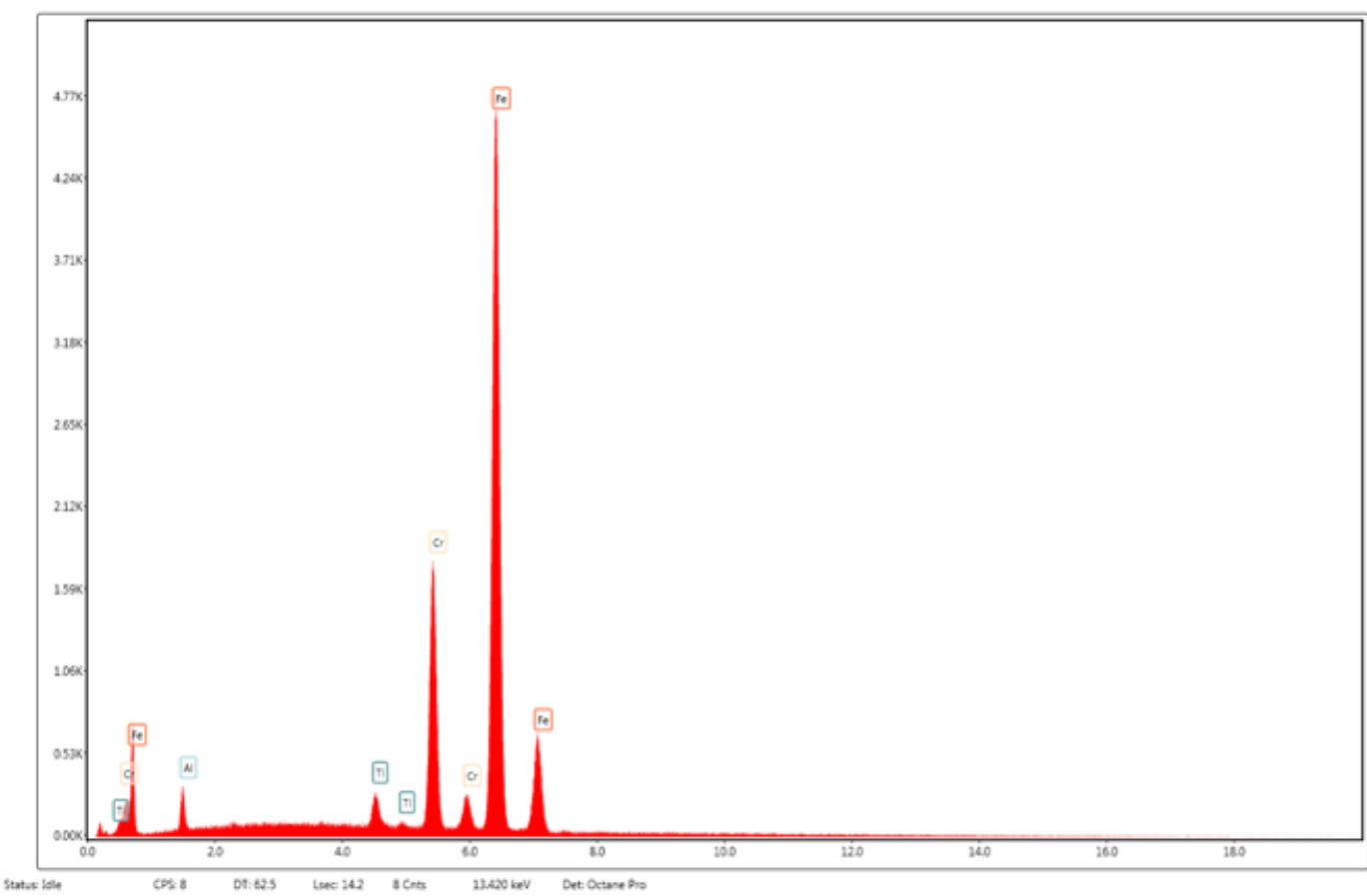

Fig. 7. The distribution of the elements in the peripheral oxide layer for the NUC 13 alloy

(1.5\% wt Ti) 


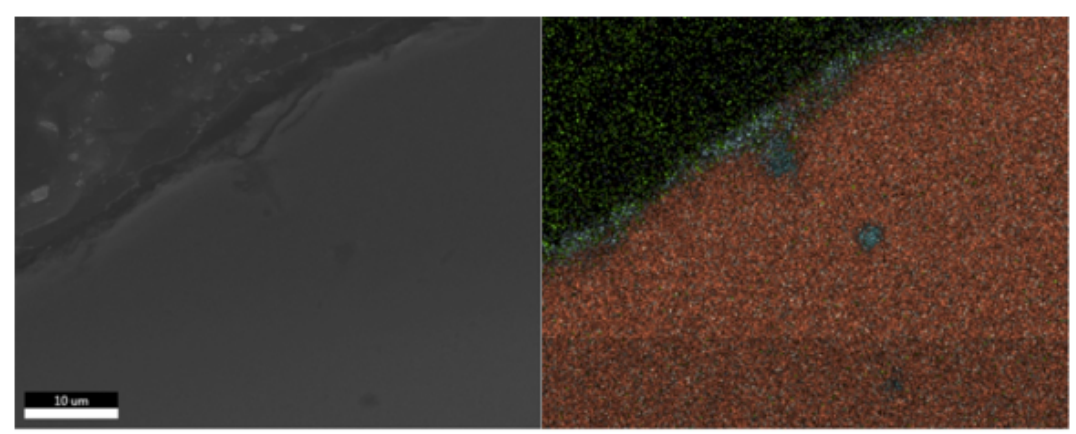

a

\section{b}

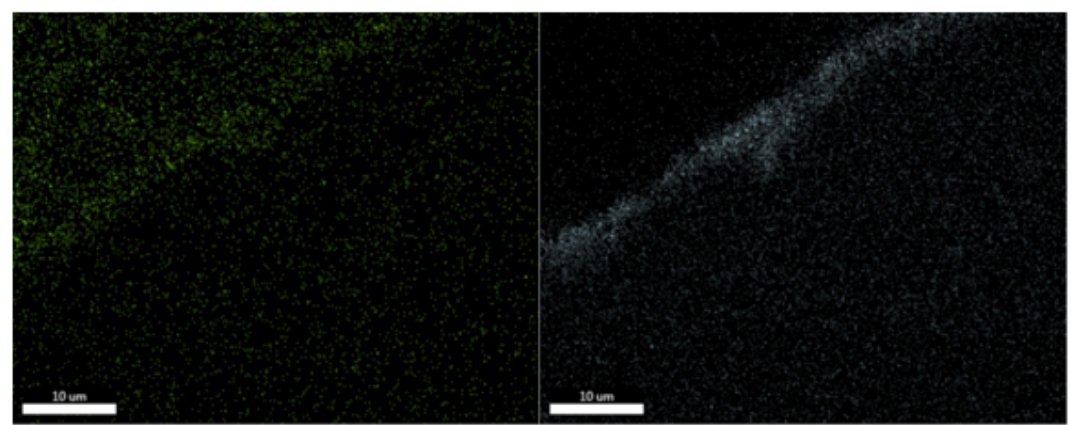

c
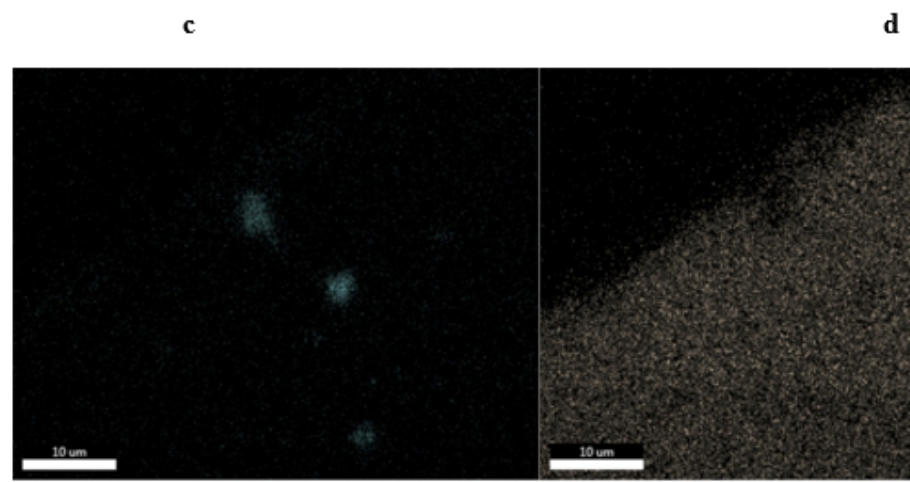

e

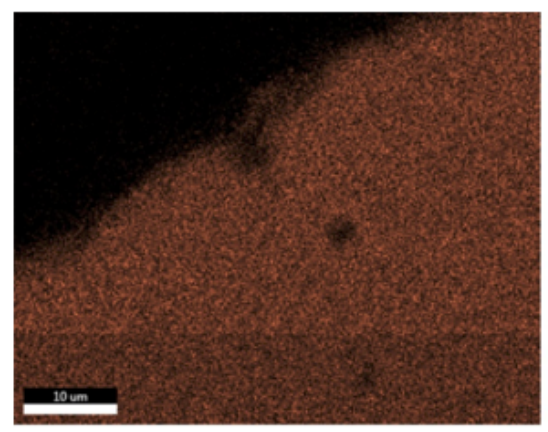

g

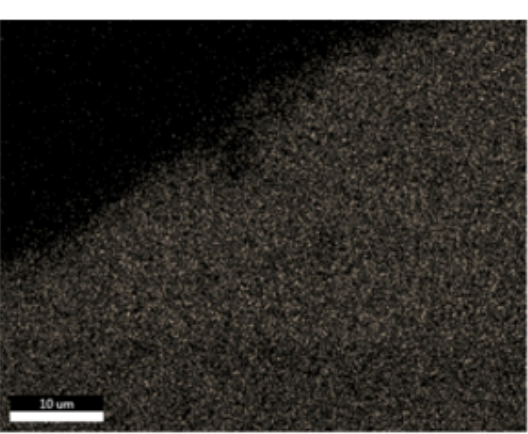

f h
Fig. 8 Distribution of the chemical elements in the oxide layer in the case of the NUC 13 sample: a. SEM image of the oxide layer (2000x); b. All chemical elements (1600x); c. O K;

d. Al K; e. Ti K; f. Cr K; g. Fe K; h. Component values

\begin{tabular}{|c|c|c|c|c|c|c|}
\hline Sample & \multicolumn{5}{|c|}{ Individual values $^{*}$} & Average value, $\mathrm{HV}_{0,2}$ \\
\hline NUC 11 & 178 & 183 & 182 & 183 & 187 & 183 \\
\hline NUC 12 & 176 & 167 & 175 & 176 & 174 & 174 \\
\hline NUC 13 & 167 & 165 & 160 & 163 & 160 & 163 \\
\hline
\end{tabular}

Table 4 MICROHARDNESS VALUES $\left(\mathrm{HV}_{0.2}\right)$

AIK $\alpha, \mathrm{CrK} \alpha$, FeK $\alpha$, TiK $\alpha$ and OK $\alpha$ (sample NUC 13 ) is show $n$ in figure 8.

Microhardness measurements

Microhardness measurements HV0.2 were made using a Shimadzu HMV 2TE testing machine, with a measuring force of $1.9614 \mathrm{~N}$, measurement duration of 10 seconds and an extended relative uncertainty of $1 \%$. The measurement results of microhardness for the three analysed samples are presented in table 4.

The primary analysis of the experimental data shows that there is a quasi-constancy of the microhardness values, which reflects an increased homogeneity of all samples obtained in the VAR furnace. For all the samples, one can observe that there is a narrow variation of the microhardness values, in the range of 163-183 HV0.2, solely due to the influence of the alloying elements in the metal alloy composition and to the uniform layout of the constituents in the metal matrix. The Vickers microhardness values for these alloys are higher than of other similar alloys microalloyed with hafnium [26]. Furthermore, there is a downward trend of microhardness 
with the increase of the $\mathrm{Ti}$ content in the chemical composition of the alloy.

\section{Conclusions}

This research is aimed at obtaining and characterizing the FeCrAl alloy, microalloyed with titanium, potentially usable in nuclear power plants (generation 4R, type LRF). To highlight the effect of alloying with titanium on the mechanical and microstructural characteristics of the alloy, especially on the superficial oxide layers, three batches of FeCrAl alloy with variable content of titanium $(0.5 \%$ wt Ti, $1.0 \%$ wt Ti and $1.5 \%$ wt Ti) were obtained. The EDAX analysis performed in the central zone of the samples shows a similitude between the designed and the obtained chemical composition. The Ti distribution reflects the homogeneity of the alloy, the content of this element in the surface oxide layer increases with the increase of the $\mathrm{Ti}$ content in the alloy.

The microstructural aspect of different areas, located in the cross section, shows that the surface layer contains complex oxides of elements like aluminium and titanium, whose proportions are given by the concentration of these elements in the alloy composition. The chemical composition of the marginal crust of the samples microalloyed with titanium indicates that the value of the Ti content is increasing with the increase of the amount of titanium in the alloy. The simultaneous presence of the two elements with very high affinity for oxygen (aluminium and titanium), contribute to the formation of complex oxides of Al and Ti, whose share is given by the amounts of these elements in the alloy. The oxide thickness is variable, ranging from 5.247um (NUC 12) and 20.04 im (NUC 13).

The hardness values for FeCrAl alloys microalloyed with titanium are within the range of 163-183 HV0.2, the normal limits for these materials. This is mainly due to the influence of the alloying elements in the metal alloy composition and to the uniform distribution of the metallographic constituents in the metal matrix.

Acknowledgments: The research work was financially supported by the Romanian National Program for Research within the framework of the Project No. PCCA 243/2014 Advanced Metallic Materials used for the New Generation of Nuclear Power Plant 4R - NUCLEARMAT.

\section{References}

1.PILLIS, M.F., RAMANATHAN, L.V. Mater Res, 7, No. 1, 2004, p. 97. 2.CHECMANOWSKI, J., MATRASZEK, A., SZCZYGIEE, I., SZCZYGIEf, B. J Therm Anal Calorim, 2013, p.113.

3.HOSEMANN, P., HAWLEY, M., KOURY, D, SWADENER, J.G., WELCH, J., JOHNSON, A.L., MORI, G., LI, N. J Nucl Mater 375, 2008, p. 323.
4.CARO, M., WOLOSHUN, K., RUBIO, F., MALOY, S. Advanced SMR Materials Development, Small Modular Reactors Research and Development Program, Los Alamos National Laboratory, 22 March, 2013.

5.KURATA, Y., SAITO, S. Mater Trans, 50, No. 10, 2009, p. 2410.

6.YASKIV, O.I., FEDIRKO, V.M. International J ournal of Nuclear Energy, Volume 2014.

7.ALLEN, T. R., CRAWFORD D. C. Science and Technology of Nuclear Installations, Volume 2007, Article ID 97486.

8.LIM, J., NAM, H.O., HWANG, I.S., KIM, J.H.J Nucl Mater 407, 2010, p. 205.

9.LIM, J., HWANG, I.S., KIM, J.H. J Nucl Mater 441, 2013, p. 650.

10.M. DEL GIACCO, M.D., WEISENBURGER, A., SPIELER, P., ZIMMERMANN, F., LANG, F., JIANU, A., MUELLER, G. Wear 280-281, 2012, p. 46

11.PILLIS, M.F., CORREA, O.V., DE ARAUJ O E.G., RAMANATHAN, L.V. Mater Res, 11, No. 3, 2008, p. 251.

12.JIANU, A., WEISENBURGER, A., HEINZEL, A., FETZER, R., DELGIACCO, M., AN, W., MUELLER, G., VOICULESCU, I., GEANTA, V. European Congress on Advanced Materials and Process, EUROMAT 2011, 12-15 September 2011, Montpellier, France.

13.GEANTA, V., VOICULESCU, I., STEFANOIU, R., JIANU, A. Met Intl, XVI, no. 5, 2011, p.153.

14.AMANO, T., TAKEZAWA, Y., SHIINO, A., SHISHIDO, T.J Alloy Compd 452, 2008, p. 16

15.CHECMANOWSKI, G.J ., SZCZYGIE, J. Mater Chem Phys 139, 2013, p. 944.

16.NAUMENKO, D., COZE, J.L., WESSEL, E., FISCHER, W., QUADAKKERS, W.J. Mater Trans, 43, No. 2, 2002, p. 168.

17.PINT, B., GARRATT-REED, A., HOBBS. L. J PHYS IV, 1993, p. 247.

18.AMINORROAYA-YAMINI, S. Effect of titanium additions to low carbon, low manganese steels on sulphide precipitation. PhD thesys, Engineering Materials Institute, University of Wollongong, 2008.

19.BEIDOKHTI, B., KOUKABI, A.H., DOLATI, A. Mater Charact 60, 2009, p. 225.

20.GEANTA, V., StEFANOIU, R., VOICULESCU, I. Rev. Chim. (Bucharest), 65, no. 1, 2014, p. 94

21.*** www.eramet.wix.com/eramet.

22.VOICULESCU, I., RONTESCU, C., DONDEA, L. Metalografia imbinarilor sudate. Editura Sudura, Timisoara, 2010.

23.GEANTA, V., VOICULESCU, I., STEFANOIU R., Rev. Chim. (Bucharest), 64, no. 11-12, 2013, p. 1441.

24.*** www.lamet.ro.

25.*** $w$ ww.metav-cd.ro.

26.GEANTA, V., VOICULESCU, I., STANCIU, E.M. Intl. Conference on Innovative Research, May 19-20 2016 - ICIR Euroinvent. IOP Conf. Series: Materials Science and Engineering, 133, 2016, UNSP 012016, doi: 10.1088/1757-899X/133/1/012016.

Manuscript received: 23.05 .2018 